\section{Bambuí Project: a qualitative approach to self-medication}

\author{
Projeto Bambuí: uma abordagem qualitativa \\ na investigação da automedicação
}

\begin{abstract}
Representations related to self-medication were investigated, seeking to identify contextual elements that can reinforce or inhibit such practice. An anthropological approach based on the model of signs, meanings, and actions was used. Twenty-nine inhabitants from the town of Bambuí, Minas Gerais State, Brazil, were interviewed (17 women and 12 men), selected among participants in a health survey that had been on medication in the previous 90 days. The research focused on the identification of different types of self-medication practiced by the interviewee or by a relative, and then "ways of thinking and behaving" associated with this practice were investigated. The influence of pharmacists/drugstore sales attendants as well as family and friends, perception of the health problem as transitory and a minor issue, familiarity with and easy access to certain pharmaceuticals, as well as difficulties in access to (and negative as sessment of) health care were determinant factors for self-medication.
\end{abstract}

Anthropology; Self Medication; Qualitative Research
Antônio I. de Loyola Filho 1,2

Maria Fernanda Lima-Costa 1,2

Elizabeth Uchôa 1,2

\section{Introduction}

Self-medication can be considered the most common form of self-care in health. Paulo \& Zanini ${ }^{1}$ define self-medication as the use of a product for the treatment of a disease or symptom or for disease prevention or promotion of health, without a professional prescription.

Self-medication can take place through the consumption of industrialized or manipulated medicines, or the use of home remedies (teas, herbs, etc.) and includes various types of activities: acquiring medicines without a prescription 2,3 , resubmitting old prescriptions to purchase medicines 4 , sharing medicines with relatives or members of one's social circle 5 , using leftover medicines stored at home 6 , or failing to comply with the professional prescription, either by prolonging it or interrupting it too early or decreasing or increasing the originally prescribed dosage 5,7 .

Economic, political, and cultural factors have stimulated a constant increase in selfmedication worldwide, turning this practice into a major public health problem. Although there is currently a huge amount of medicines available on the market, this does not equate with an improvement in quality 8 . This fact should be viewed as part of the context of economic globalization and its repercussions on social investments by states. In the less developed countries, the population's access to pub- 
lic health services becomes more problematic, aggravating an already perverse context of scarce and poorly distributed and managed resources, in addition to lack of control over the production, distribution, and commercialization of pharmaceutical products ${ }^{9}$. Meanwhile, in the developed countries, public and private health plans have been restricting their coverage of expenditures on prescription drugs 10 , even as the pharmaceutical industry has pressured to turn prescription only medicine (POM) into over-the-counter (OTC) drugs, made available to consumers without mandatory presentation of a professional prescription 11 .

The currently prevailing health care model based on the "technology-industrializationcure" tripod 12 has transformed medication into a symbol for health 13 , thereby increasing the demand for prescriptions during the health professional-patient encounter 14 . Often the differences between medical and lay explanatory models 15 are not resolved during the consultation and generate discontent and non-compliance by the patient in relation to the professional prescription ${ }^{9}$. Such a context increases the possibility of various modalities of self-medication. In the attempt to save time and money on a medical appointment that fails to meet their expectations, patients turn to medicines, very frequently through drugstore sales personnel, for the answer to their problems 3,7,12,16,17.

In general, epidemiological studies have attempted to describe self-medication in terms of its prevalence in study populations 18,19 , the most widely consumed drugs $2,4,20$, and the factors associated with this practice 5,21 . In a recent study in Brazil, Loyola Filho et al. 22 observed in the town of Bambuí, Minas Gerais State, that $46 \%$ of the persons who had consumed some medicine in the previous three months had used non-prescribed drugs. According to this study, the factors independently associated with self-medication were male gender, age bracket (older participants used fewer non-prescribed drugs), more individuals residing in the household, fewer medical visits, consultation with a pharmacist, and less expenditure on medication.

Some authors have called attention to the need to capture the implicit symbolic content of self-medication 21 in order to achieve a more in-depth understanding of this practice 5,23 . According to others 24,25 , such studies would help adjust policies to local realities vis-à-vis the use of medicines.

Uchôa \& Vidal 26 contend that adequate policies can only be obtained when one considers that people's way of thinking and acting is mediated by the social and cultural context to which they belong. Anthropological studies in health aim to identify and analyze the mediation exerted by social and cultural factors in the construction of characteristic ways of thinking and acting towards health and disease. The approach used in these studies allows an understanding of the practices developed to solve health problems, as well as a grasp of the underlying structural aspects, norms, values, and symbols 27.

In developed countries, culturally defined migrant communities have been the object of studies on at-home self-medication with injected medication, focusing on clashes between culturally rooted habits and legal and financial constraints on such practice, with the risk of AIDS transmission as the backdrop 28,29. In less developed countries, quantitative and qualitative methods have been used to investigate how interactions between drugstore customers and sales attendants and owners can influence selfmedication 3,14. In Brazil, qualitative studies have shown the relevance of self-medication as a strategy for consumption of health-related goods 16 , deriving from the ease in acquisition of medicines 7 .

In the current study, the anthropological approach was used to investigate the underlying representations concerning self-medication among residents of the town of Bambuí, aimed at identifying the contextual elements that in some way reinforce or inhibit this practice.

\section{Methodology}

\section{Study area}

This study was conducted in the town of Bambuí, with some 15 thousand inhabitants, located in western Minas Gerais State, Brazil. The main economic activities in the municipality (county) of Bambuí are agriculture/cattle-raising and commerce. In 1990 and 1991, the Human Development Index was 0.70 , life expectancy at birth 70.2 years, and $75 \%$ of the deaths occurred in individuals 50 of age or over. The town had a general hospital with 62 beds and one physician per one thousand inhabitants. Further details can be found in LimaCosta et al. 30 .

The Bambuí Project, conducted in the town of the same name, has two components: (1) a general population health survey and (2) a prospective health study in the elderly. The current study refers to data collected in the population participating in the health survey. 


\section{Study population}

The Bambuí Health Survey was conducted with a simple probabilistic sample of residents 5 years of age or older. Subjects were identified through census data 30 . Selection for the abovementioned epidemiological study on self-medication 22, included all 796 participants from the sample 18 years of age or older who reported having taken at least one medicine (prescribed or non-prescribed) in the 90 days prior to the interview. Of these, 39 were randomly selected for the study (29 participated).

\section{Data collection and analysis}

Data collection and subsequent analysis were based on the model of "signs, meanings, and actions system" developed by Corin and collaborators $26,31,32$. The point of departure for this model is study of concrete actions related to the target event in order to capture the determinant logic, as well as to identify contextual elements influencing the materialization of such logics in specific situations. The model assumes that the universe of health-related problems and events is specific to each population, and that this specificity derives from cultural particularities and the macrostructure to which each population belongs. According to this model, contextual elements such as the social dynamic and central cultural codes and norms, among others, define the way people identify and evaluate a health-related problem or event and act towards it. This model aims at a systematic knowledge of populations' way of thinking and acting towards events related to the health-disease process 26 . The analysis of the signs, meanings, and actions is based on the practices of actors as grasped by concrete histories $26,31,32$.

To reconstruct the universe of representations (ways of thinking) and the behavior (ways of acting) associated with self-medication, 29 in-depth interviews were performed. The interviews were held in the interviewee's home or at the Emmanuel Dias Health Extension Center of the Oswaldo Cruz Foundation in Bambuí, lasting 30 and 60 minutes. Each interview began with the question: "In the last 3 months, did you take any medicine, shots [injections], pills, capsules, or syrup?". This was the point of departure for investigating the various modalities of self-medication, personal characteristics of individuals who practiced versus did not practice self-medication, the medicine used, the health problem treated, and use of and access to health care services. When the interviewee reported use of medicines, the interviewer asked for the name of the drug, the reason for its use and who had indicated it. When interviewees denied having taken medicine in the previous three months, they were asked whether any family member living in the same household had done so. The interview proceeded by seeking to identify the interviewee's perception of the event. The interview also focused on situations in which self-medication was not practiced, in order to understand the logic behind this conduct. The following questions concentrated on practices that might facilitate selfmedication, like storing leftover prescription drugs in the household. Changes in relation to the prescription itself were also explored, identifying situations in which it was not followed correctly (extension or early interruption of treatment) or in which the prescription was reutilized. In addition, the interview sought to identify which criteria were used to favor (or disregard) a medicine when the prescription was not fully dispensed. The interviews were taped with a miniature tape recorder and later transcribed and keyed in.

The analysis of the set of interviews began with a close reading, identifying the significant units. Next, analytical categories were created that allowed to group all the significant units with a minimum of ambiguity. During an initial (quantitative) stage, the most common categories were identified. The next stage involved an analysis of the connections between the various analytical categories, seeking to unveil interactions between conceptual logics and underlying contextual elements in self-medication.

In the description of results, the set of letters and numbers that appears in parentheses refers to the interviewee's identification. The letters FI indicate that the interviewee is a female and MI a male; the numbers show the sequence in which the interviews were held.

\section{Results}

A total of 12 men and 17 women were interviewed, ranging in age from 22 to 83 years. The majority ( 8 men and 15 women) stated having used self-medication. Many (4 men and 10 women) also reported that other members of their families had practiced self-medication. Only four men and two women reported not having used self-medication. Of these, two men stated that they had not consumed any medication at all in the previous 90 days, and one (MI2, 40 years) explained that he had not need- 
ed any medication because he was healthy, although he had the habit of keeping medicines at home in case they were needed.

\section{Modalities of self-medication}

Different modalities of self-medication were mentioned by the interviewees: consumption of medicines acquired without a professional prescription, reuse of old prescriptions, shared use of medicines, non-compliance with professional prescriptions, and used of leftover medicines stored at home.

The most frequently cited modality was the acquisition of medicines without a prescription (13 informants). In some cases the interviewee referred to more than one episode of self-medication in the family. Even psychoactive drugs can be purchased without a medical prescription, as revealed by one interviewee: “[the pharmacist] didn't want to sell me the drug, because a prescription was required, so I said, 'I'm saying, it's the doctor's orders.' So he sold me the drugs. The pharmacist is my friend, and the doctor is, too" (MI26). Reutilization of old prescriptions and shared use of medicines were generally associated with prior experience with the medication either by the interviewees themselves or some family member. Non-compliance with the professional prescription in the form of early interruption of treatment was frequently associated with a perceived improvement in symptoms and underrating of the problem: "I didn't give the dose the doctor had recommended, I gave less. I said to myself, this should be enough, it's probably nothing serious, right?" (FI24, concerning an antemetic administered to her son). Fear of aggravating the clinical state and addiction to the prescribed drug were also mentioned to justify non-compliance with the physician's prescription. Use of leftover medicines kept at home appears to be a strategy developed to deal with unforeseen needs, especially when access to medical care is not possible. This trend appears in the following interview: "Sometimes a headache, a muscle ache in my arm, all of a sudden a toothache in the middle of the night, there's no clinic open, and if you go to the hospital without any money you can't get treated" (MI15).

Self-medication was generally viewed in a negative light both by those who practice it and those who do not. People who self-medicate justify this practice as a custom and see themselves as complacent, sloppy, or uninformed. Meanwhile individuals who do not use medication without a prescription describe the practice as the result of error, ignorance, or even ir- responsibility. In the latter case, we highlight an excerpt from an interview with a mother (FI24), explaining why she doesn't give any medication to her son with a doctor's prescription: "With my kid, how am I supposed to give him just anything? You think I'm crazy? My son has his own system, and another kid's system is different. He could get poisoned, something could happen, and he could die. And it would be my fault".

\section{Choice of medication}

The choice of medication can be influenced by various factors. Sometimes the pharmacist or drugstore attendant recommends the medicine. Other times it is the physician himself who authorizes the use of a given drug if a given symptom appears or persists. However, oftentimes it is lay people who influence the choice of medication: there were several reports of medicines consumed on the basis of advice by family, friends, or even neighbors.

Some attributes of a drug can make it particularly prone to use in self-medication. Individuals tend to favor medicines with which they have prior experience (i.e., which they used previously in similar situations) and which proved effective (which worked previously and will probably work again). The place where the medicine can be acquired and the ease in obtaining it are also determinants in the choice: "It's common, right? Everybody has that drug, everybody keeps it at home, and even mom-and-pop stores sell it" (MI15).

In relation to non-compliance with a physician's prescription, a negative assessment of a drug's efficacy is the most frequently cited reason for deciding to abandon treatment: "He prescribed some medicines, and I took them, but I didn't get any better. Then I bought some other medicine that somebody else had told me was good" (FI19). Another factor is the cost of medication: individuals fail to purchase prescribed medication if they consider it expensive. They also refer to unwanted side effects and the fear of the medication becoming habit-forming. One interviewee reported dropping out of her hormone replacement therapy because of the side effects she attributed to it: "I dropped it. About two months ago I stopped. I'm not happy, because I never had stretch marks before, but now I do" (FI27). Another female interviewee, who was feeling better from her depression, explained that she had abandoned her prescription treatment because of fear of addiction: "I got better from my depression, so I said, 'Look, I'm not going to keep taking the medication, be- 
cause it's habit-forming" (FI06). Another interviewee expressed his fears, reporting on his sister's experience: “I don't like to take medicine, because it's addictive. I've got a sister, like when she's got a headache she takes a whole bottle of medicine. That's a disease, it's doesn't make you any better! I think the person gets addicted to it" (FI24).

\section{Types of health problems}

The analysis of the set of interviews pointed clearly to a distinction by interviewees between health problems that can be treated by selfmedication and those that should not be. Aches and pains, particularly headaches (13 citations) and colds (7) were the problems most frequently mentioned as the targets of self-medication. Meanwhile, fever is viewed as a problem that demands medical attention; self-medication is indicated merely to keep the fever under control while waiting for medical care: "The only thing I give them is [drug $\mathrm{ABC}$ ] for fever. I give them the medicine and then take them to the doctor. I don't sit around home with them when they have a fever, because it's not easy for a kid to get over a fever" (FI24). High blood pressure is also viewed as a health problem that requires medical attention. One individual even distrusted the doctor's instructions, but ruled out selfmedication because of fear of getting worse: "I didn't really trust what the doctor told me, that there's no cure, but I'm afraid of a heart attack, you know, one of those diseases that comes with high blood pressure" (MI27).

In general, self-medication appears to be viewed as indicated for transitory, non-serious problems. The interviewees classified such problems as passing, temporary, or banal. Meanwhile, they do not appear to see self-medication as indicated for more serious or persistent problems. The notion of a problem's severity can be linked to a given area of the body; for example, the chest is seen as the site of serious diseases: "In my opinion, chest pain is more serious, or palpitation, a speed-up in your heartbeat" (MI15). The perception of severity can also be associated with the notion of incurability, as explained by one interviewee who explained why his wife (unlike himself) did not use selfmedication: "She doesn't take medication on her own. She has this bad disease, diabetes, they say there's no cure for it, and there's no cure for arthritis in the bones. That's what everybody says, including the doctors: there's no cure" (MI20). The same interviewee associated a disease's severity with death: "Constipated intestines, labyrinthitis, these aren't serious diseases, other- wise I'd be dead already, you know? For fortysome years now I've had these ailments," referring to the fact that he takes laxatives and medication for labyrinthitis, with or without a medical prescription.

Another characteristic that influences selfmedication is familiarity with a given problem. In general, a familiar health problem is treated with self-medication, unlike unknown problems, for which professional help is sought: "And other diseases that we don't know what they are, the doctor has to know. Like this thing I had the other day. Got sick, didn't know what it was, went to the doctor, and found out" (MI13).

\section{Medical care}

The analysis of the interviews as a whole highlighted that self-medication practices are viewed as substitutes for formal health care when the latter is perceived as inaccessible, unaffordable, or unsatisfactory. Often the option for self-medication is because services are viewed as expensive, full of red tape, slow in meeting the user's needs, and a source of complications for those who turn to them. One interviewee stated quite clearly that taking medicine is much cheaper than going to the doctor: "It's much simpler to take some medicine than to see the doctor, because he's too expensive, and the public health system is basically useless, because they tell you to go see your own physician. So you end up paying anyway" (MI09). Another discouraged reaction relates to the excessive bureaucracy involved in securing a doctor's appointment: "I prefer to stay home rather than stand on line for an appointment. There's so much red tape, that sometimes when I feel sick I just sit it out at home" (MI15). Another interviewee emphasizes the difficulties that end up impeding access to care: "It's complicated, because you get there and have to wait on line. You have to show up in the middle of the night to get an appointment for the next day, for the doctor to see you by eleven. So you waste an entire day" (MI28).

However, the fact that one gets an appointment does not always prevent self-medication. Sometimes self-medication is a spin-off from dissatisfaction with the quality of care received. Frustration and dissatisfaction with care received result from the perception that one's health problem did not receive the proper professional attention or that the professional was incapable of solving it. Such feelings are perceptible in the following fragments of discourse: "For example, at the social-security or public health care system, you get poor treatment. They 
just run you right through like you're on a conveyor belt. It's almost like they couldn't care less. So this may discourage people from going to the doctor. The person says, hey, it's more practical to go buy the medicine and take it on your own" (FI27); "He [the physician] said to me, 'I'm not sure what medicine is good for gastritis, but if you wish to consult another physician...', so I got discouraged with the appointment. He didn't prescribe anything, so I spoke to my nephew, who brought me these pills" (FI22).

Self-medication can also be seen as a first step in the attempt to solve a health problem. Six interviewees reported having gone for medical care after self-medication failed to solve their health problem, as in the following interview: "My husband had this terrible itching on his back, and he used self-medication, tried all kinds of medicine and nothing took care of it, so he went to a doctor, a dermatologist" (FI27).

Ten different individuals referred to situations in which the physician had suggested (or even recommended outright) that they use medication without his supervision. One interviewee mentioned the name of three different drugs used by his wife and which "...the doctor recommended that she take during her crisis periods with her headaches" (MI18), thus describing how his wife used off-prescription analgesics.

\section{Discussion}

The various modalities of self-medication reported in the literature were mentioned/identified in the current study, with the most frequently cited form being purchase of medicines without prescription in drugstores (or, less frequently, in grocery stores, "shops", or similar commercial establishments).

At drugstores, the pharmacist or sales attendant is generally the person who determines which medicine is used, thus demonstrating that people trust in his ability to prescribe. This participation by drugstore sales attendants in self-medication activities has also cropped up in studies conducted in other developing countries besides Brazil. Based on ethnographic research in India, Kamat \& Nichter 3 describe various modalities of this behavior, highlighting the cultural and socioeconomic context in which it occurs and how the relations between drugstore owners, sales attendants, and drug company sales reps influence it. Likewise, although the purchase of psychoactive drugs without a medical prescription is prohibited in Brazil, it appears to have been facilitated in our study population by relations of friendship between users, physicians, and pharmacists, hence confirming the results of a study by Rozemberg 7 among farmers in the Brazilian State of Espírito Santo.

Keeping medicine at home is a common practice in our study population. The medicines that are stored at home may be left over from a previous prescription or have been acquired specifically for this purpose, that is, potential future use. At any rate, keeping medicines available in the home is virtually considered an obligation, since they are seen as definitely necessary to treat problems that can occur at times when medical care is not available.

Individuals who practice self-medication ascribe their attitude to habit, agreeing that this practice can reflect a kind of "sloppiness" towards health. Those who do not self-medicate are more emphatic in condemning the practice, describing those who do so as "wrong", "foolish", and even "ignorant".

The medicine chosen for consumption without a prescription has mutually reinforcing characteristics: it should be familiar, common, effective, and easy to obtain. The definition of an effective medicine is one that has worked before, while a common medicine is one that everyone has, and therefore that everyone is familiar with. Ease of purchase is sometimes related to the fact that such drugs are sold overthe-counter in "grocery stores" or "mom-andpop stores".

Some health problems appear to be treated preferentially with self-medication. This appeared clearly in the references to the custom of using non-prescribed medicines to treat headaches and colds, problems that are familiar (or "common") and dispense with a medical appointment. Beckerleg et al. 14 found similar results in Palestine. Other health problems appear to contraindicate the use of self-medication, such as fever and alterations in blood pressure. The distinction between health problems for which self-medication is or is not allowed is based on the perception of certain attributes of the problem (duration, familiarity, degree of severity, and intensity). Transitoriness and persistence indicate, respectively, the possibility of self-medication and the need to seek medical care. The same opposition is perceived in relation to familiarity versus non-familiarity with a health problem: with familiar problems it is possible to get by without the doctor, whom however is seen as essential to treat what is strange or "different". In relation to the degree of severity and intensity of clinical signs and symptoms, the more severe and 
intense they are, the more individuals tend to rule out the possibility of self-medication. Classifying a health problem as serious means to interconnect the notions of impossibility of cure and the risk of dying, not to mention the area of the body in which the problem manifests (the chest is highlighted, which in turn may be related to the fact that it houses what individuals recognize as vital organs, namely the lungs and heart). Finally, the disappearance of symptoms may be interpreted as a sign of normalcy or cure, leading to mid-course treatment dropout.

The abandonment of medically prescribed treatment can also result from a negative assessment of the medicine's efficacy, the existence of side effects, and fear that the drug will cause addiction. There is thus an apparently contradictory feeling in relation to the drugs used in self-medication: the more one uses a medicine, the more reliable it is; yet at the same time, one believes that its continuing use can lead to addiction.

We should highlight the complexity of the relationship established by the informants between self-medication and recourse to formal health care services. On the one hand, self-medication can be seen as a first step in the search for resolution of health problems, or even as a more accessible substitute for formal care. In a study in a community of Latino migrants in the United States, difficulties in access to formal health care services were incriminated for the home consumption of injected medication 29 . In addition, self-medication can be encouraged by dissatisfaction with the quality of the care received. In our study, this dissatisfaction is expressed most frequently (but not exclusively) in relation to public health care services or those outsourced by the government. Dissatisfaction over the care received begins with the hurdles involved in seeking medical care, especially the time spent to secure a doctor's appointment. There is also the notion that consultations are too quick and that the doctors hardly speak to the patients, omit orientation and opinions, and deny patients the opportunity to effectively express their problems. A negative assessment of the physician-patient encounter can stimulate self-medication, as emphasized by Queiroz 16 .

Physicians themselves can also encourage patients to practice self-medication. Permission to use a drug continuously or reissuing prescriptions without a new patient work-up can be interpreted as tacit approval of self-medication. Nichter \& Vuckovic 17 call attention to the need to investigate the use of self-medication in the treatment of chronic conditions, since it is common to rely on previously prescribed medicines, without the physician's supervision.

Several results from the current study corroborate observations from an epidemiological study in the town of Bambuí 22, showing a lower frequency of self-medication among individuals with a chronic disease diagnosis and among those with fewer medical visits in the previous year. These results are consistent with the notion that persistent and serious health problems are not prone to self-medication, and that self-medication is used as a substitute for formal health care. Consulting the pharmacist, keeping medicines at home, and sharing medicines with family members are strategies developed to circumvent such situations.

In short, the results of this study show that although the physician's knowledge and competence are recognized, underlying the selfmedication practice is the idea that the doctor is not the only one who knows how to prescribe. Very frequently, pharmacists and drugstore attendants, family members, friends, and neighbors are heard. Furthermore, the logic governing consumption of non-prescribed medicines is linked more closely to representations of the health problem as experienced and the availability of medical care than to the characteristics of the individual experiencing the problem or the drug used.

The results reinforce the need for health professionals (and especially those who are legally authorized to prescribe) to be alert to the highly frequent possibility that their patients self-medicate. To investigate this practice with their clients, to be alert to the lay concepts and ideas about the health problem and the drug used in the treatment, and to provide appropriate orientation during the patient visit are concrete measures which can decrease the risk of inadequate use of drugs and the occurrence of side effects and accidents related to this practice. 


\section{Resumo}

Foram investigadas representações subjacentes à prática da automedicação, procurando-se identificar elementos contextuais que de alguma maneira reforçam ou inibem essa prática. Para tal, utilizou-se uma abordagem antropológica baseada no modelo de "Signos, Significados e Ações". Foram entrevistados 29 moradores da cidade de Bambuí, Minas Gerais, Brasil (17 mulheres e 12 homens), selecionados aleatoriamente entre participantes de um inquérito de saúde, que haviam consumido algum medicamento nos últimos noventa dias. Buscou-se identificar distintas modalidades de automedicação praticadas pelo entrevistado ou por algum familiar e, a partir daí, investigou-se as "maneiras de pensar e de agir" associadas a esta prática. Verificou-se que, a influência do balconista da farmácia, familiares e amigos, a percepção do problema de saúde como transitório e sem gravidade, a familiaridade e facilidade de acesso a certos medicamentos, bem como a disponibilidade e a percepção do atendimento médico recebido como de pior qualidade, foram fatores determinantes da automedicação.

Antropologia; Automedicação; Pesquisa Qualitativa

\section{Collaborators}

A. I. Loyola Filho collected, transcribed, and analyzed the data and wrote the article. E. Uchoa provided orientation for the article, in addition to designing the study and supervising the data analysis and drafting of the article. M. F. Lima-Costa played a central role in the discussion and design of the study, results, and critical review of the article.

\section{References}

1. Paulo LG, Zanini AC. Automedicação no Brasil. Rev Assoc Med Bras 1988; 34:69-75.

2. Drug Utilization Research Group. Multicenter study on self-medication and self-prescription in six Latin American countries. Clin Pharmacol Ther 1997; 61:488-93.

3. Kamat VR, Nichter M. Pharmacies, self-medication and pharmaceutical marketing in Bombay, India. Soc Sci Med 1998; 47:779-94.

4. Greenhalg T. Drug prescription and self-medication in India: an exploratory survey. Soc Sci Med 1987; 25:307-18.

5. Segall A. A community survey of self-medication activities. Med Care 1990; 28:301-10.

6. Wilkinson IF, Darby DN, Mant A. Self-care and self-medication: an evaluation of individuals' health care decisions. Med Care 1987; 25:965-78.

7. Rozemberg B. O consumo de calmantes e o "problema de nervos" entre lavradores. Rev Saúde Pública 1994; 28:300-8.

8. Acevedo DV, Valle AA, Toledo JLM. Características de la adquisición de medicamentos en Morelia (Michoacán, México). Bol Oficina Sanit Panam 1995; 119:237-42.

9. Fabricant S, Hirschhorn N. Deranged distribution, perverse prescription, unprotected use: the irrationality of pharmaceuticals in the developing world. Health Policy Plan 1987; 2:204-13.

10. Blenkinsopp A, Bradley C. Patients, society and the increase in self-medication. BMJ 1996; 312 : 629-32.

11. Bradley C, Blenkinsopp A. Over-the-counter drugs: the future of self-medication. BMJ 1996; 312:835-7.

12. Haak H. Padrões de consumo de medicamentos em dois povoados da Bahia (Brasil). Rev Saúde Pública 1989; 23:143-51.

13. Lefèvre $F$. A função simbólica dos medicamentos. Rev Saúde Pública 1983; 15:500-3.

14. Beckerleg S, Lewando-Hundt G, Eddama M, Alem A, Shawa R, Abed Y. Purchasing a quick fix from private pharmacies in the Gaza Strip. Soc Sci Med 1999; 49:1489-500.

15. Kleinman A. Patients and healers in the context of cultures: an exploration of the borderland between anthropology and psychiatry. Berkeley/Los Angeles: University of California Press; 1980.

16. Queiroz MS. Estratégias de consumo em saúde entre famílias trabalhadoras. Cad Saúde Pública 1993; 9:272-82.

17. Nichter M, Vuckovic N. Agenda for an anthropology of pharmaceutical practice. Soc Sci Med 1994; 39:1509-25.

18. Mestanza F, Pamo O. Estudio muestral del consumo de medicamentos y automedicación en Lima metropolitana. Revista Médica Herediana 1992; 3:101-8.

19. Vilarino JF, Soares IC, Silveira CM, Rödel APP, Bortoli R, Lemos RR. Perfil da automedicação em município do Sul do Brasil. Rev Saúde Pública 1998; 32:43-9.

20. Arrais PSD, Coelho HLL, Batista MCDS, Carvalho ML, Righi RE, Arnau JM. Perfil da automedicação no Brasil. Rev Saúde Pública 1997; 31:71-7.

21. Lam CLK, Catarivas MG, Munro C, Lauder IJ. Self- 
medication among Hong Kong Chinese. Soc Sci Med 1994; 39:1641-7.

22. Loyola Filho AI, Lima-Costa MFF, Uchôa E, Guerra HL, Firmo JOA. Prevalência e fatores associados à automedicação: resultados do Projeto Bambuí. Rev Saúde Pública 2002; 36:55-62.

23. Tejedor N, Zafra E, Sánchez-Del-Viso Y, Muñoz AL, Vidal C, López-Castro F. Transtornos comunes de salud: autocuidado y automedicación. Aten Primaria 1995; 16:13-8.

24. van der Geest S. Pharmaceuticals in the Third World: the local perspective. Soc Sci Med 1987; 25:273-6.

25. van der Geest S, Hardon A. Drug use: methodological suggestions for field research in developing countries. Health Policy Plan 1988; 3:152-8.

26. Uchôa E, Vidal JM. Antropologia médica: elementos conceituais e metodológicos para uma abordagem da saúde e da doença. Cad Saúde Pública 1994; 10:497-504.

27. Minayo MCS, Sanches O. Quantitativo-qualitativo: oposição ou complementaridade? Cad Saúde Pública 1993; 9:239-62.

28. Flaskerud JH, Nyamathi AM. Home medication injection among Latino women in Los Angeles: implications for health education and prevention. AIDS Care 1996; 8:95-102.
29. McVea KLSP. Lay injection practices among migrant farmworkers in the age of AIDS: evolution of a biomedical folk practice. Soc Sci Med 1997; 45:91-8.

30. Lima-Costa MFF, Uchoa E, Guerra HL, Firmo JOA, Vidigal PG, Barreto SM. The Bambuí Health and Ageing Study (BHAS): methodological approach and preliminary results of a population-based cohort study of the elderly in Brazil. Rev Saúde Pública 2000; 34:126-35.

31. Corin E, Uchôa E, Bibeau G, Harnois G. Les attitudes dans le champ de la santé mentale. Repères théoriques et méthodologiques pour une étude ethnographique et comparative. Montréal: Centre de Recherche de l'Hôpital Douglas, Centre Collaborateur OMS; 1989.

32. Corin E, Uchôa E, Bibeau G, Koumare B, Coulibaly B, Coulibaly M, et al. La place de la culture dans la psychiatrie africaine d'aujourd'hui: paramètres pour un cadre de références. Psychopathologie Africaine 1992; 24:149-81.

Submitted on $05 / \mathrm{Jun} / 2003$

Approved on 17/Feb/2004 